\title{
SAFETY PROFILE OF UPADACITINIB IN RHEUMATOID ARTHRITIS: INTEGRATED ANALYSIS FROM THE SELECT PHASE 3 CLINICAL PROGRAM.
}

\author{
Cristiano Augusto de Freitas Zerbini (CEPIC, SAO PAULO, SP, Brasil)
}

\section{BACKGROUND}

Upadacitinib (UPA), a JAK1-selective inhibitor, significantly improved clinical signs and symptoms of rheumatoid arthritis (RA) in patients (pts) naïve to methotrexate (MTX) and with an inadequate response to conventional synthetic DMARDs or biologic DMARDs $(1,2,3)$.

OBJECTIVE: Assess the safety of UPA as monotherapy and as combination therapy with background csDMARDs in pts with moderately to severely active RA from the safety database of the Phase 3 clinical program.

\section{MATERIALS AND METHODS}

Treatment-emergent adverse events (TEAEs) from 5 pivotal, randomized, double-blind, controlled Phase 3 trials of UPA $15 \mathrm{mg}$ or $30 \mathrm{mg}$ QD [only in 4 trials] in RA pts were analyzed using integrated short-term and individual studies with long-term [LT] active comparator (UPA mono vs MTX; UPA 15 mg with background MTX vs originator adalimumab, ADA, events/100 patient years [E/100PY]) and integrated LT (all Phase 3 exposure; E/100PY) analyses sets.

\section{RESULTS}

3834 pts received $\geq 1$ dose of UPA $15 \mathrm{mg}(\mathrm{n}=2630)$ or $30 \mathrm{mg}$ QD $(\mathrm{n}=1204) \approx 4020.1$ PY of UPA exposure with no option to switch doses. Serious infection (SIEs) frequencies were higher on both UPA doses vs PBO. SIE rates on both UPA doses were higher vs MTX, but similar on UPA 15 mg vs ADA. Herpes zoster (HZ) frequencies and rates were higher on both UPA doses vs PBO, and vs MTX, ADA, respectively. The rates of SIE and $\mathrm{HZ}$ were higher on UPA 30 vs $15 \mathrm{mg}$. Adjudicated MACE were reported in all treatment groups including PBO. LT MACE rates were similar on UPA $15 \mathrm{mg}$ and ADA and on UPA $15 \mathrm{mg}$ and MTX mono, but higher on UPA $30 \mathrm{mg}$ mono Adjudicated VTEs occurred at comparable frequencies on UPA vs $\mathrm{PBO}$ and at comparable rates on UPA vs active comparators. Malignancy (excluding [NMSC]) rates were similar on UPA vs MTX, UPA $15 \mathrm{mg}$ vs ADA, and $15 \mathrm{vs} 30 \mathrm{mg}$. The NMSC rates on UPA $15 \mathrm{mg}$ and ADA were similar; the rate on $30 \mathrm{mg}$ was higher than $15 \mathrm{mg}$, but both UPA NMSC rates were in the range reported for RA patients treated with DMARDS4. The standardized incidence ratio $(95 \% \mathrm{Cl})$ for malignancy was not elevated vs the general population. Deaths occurred in all treatment groups.

\section{CONCLUSION}

Treatment with UPA increased the risk of SIE and HZ, but not those of VTE, MACE, and malignancy vs comparators. These data support that UPA has an acceptable safety profile in the treatment of moderately to severely active RA. 